https://doi.org/10.46344/JBINO.2021.v010i01.31

\title{
ANTIMICROBIAL AND ANTIOXIDANT PROPERTIES OF FLAVONOIDS-RICH FRACTION OF ZANTHOZYLUM ZANTHOXYLOIDES LEAF
}

\author{
*Olusola, A.O., Ogidan, T.O., Olusola, A.O., Elekan, A. O., Ekun, O.E and 1Onoagbe, I. O. \\ Department of Biochemistry, Adekunle Ajasin University, Akungba Akoko, Ondo State, Nigeria. \\ 'Department of Biochemistry, Faculty of Life Science, University of Benin, Benin City, Edo State, Nigeria.
}

Email: austinolusola@gmail.com

\begin{abstract}
This study involved assessment of antimicrobial and antioxidative properties of flavonoids-rich fraction of Z. zanthoxyloides leaf. The leaf samples were washed, air-dried and pulverized into a fine powder. This was then defatted with n-hexane and extracted with methanol for 72 hours by maceration which was sieved using cheese cloth and concentrated using rotary evaporator at $50^{\circ} \mathrm{C}$ to obtain a crude methanolic extract. Phytochemical analyses were carried out on the crude extract using standard procedure and tested for antimicrobial and antioxidant properties. Thereafter, the crude extract was subjected to fractionation to obtain a crude flavonoid-rich fraction. In vitro antioxidant activity of the flavonoid-rich extract was evaluated using 1,1-diphenyl-2-picrylhydrazyl (DPPH) radical, ferric reducing antioxidant power (FRAP), Hydrogen peroxide $\left(\mathrm{H}_{2} \mathrm{O}_{2}\right)$ scavenging activity, superoxide radical scavenging activity (SRSA) methods. The antimicrobial activities were evaluated in vitro against bacterial species. Phytochemical analyses showed the presence of flavonoids, saponins, tannins, alkaloids, anthraquinones, steroids, and cardiac glycosides except phylobatannins and terpenoids which were absent. The yield of the flavonoids-rich fraction was $3.2 \%$. The flavonoids-rich fraction showed the highest antioxidant activity when DPPH reaction was done at $\mathrm{EC}_{50} 0.4857 \pm 0.0166(\mathrm{mg} / \mathrm{ml}), \mathrm{H}_{2} \mathrm{O}_{2}$ at $\mathrm{EC}_{50} 0.7482 \pm 0.0397(\mathrm{mg} / \mathrm{ml})$, SRSA at $E_{50} 0.1267 \pm 0.0052(\mathrm{mg} / \mathrm{ml})$. The microbial investigation revealed that the fraction exhibited an inhibitory activity against the bacteria Moraxella cattarhalis at $50 \mathrm{mg} / \mathrm{ml}$, Staphlococcus aureus at $125 \mathrm{mg} / \mathrm{ml}$ and Klebsiella pneumonia at $500 \mathrm{mg} / \mathrm{ml}$ comparable to the standard antibiotic, ciprofloxacin. Thus, the flavonoids-rich fraction of $Z$. zanthoxyloides leaf appears to possess potent antioxidant cum antimicrobial potentials. This indicates its potential use as a natural source of antioxidant and antibiotic in drug design and development.
\end{abstract}

Keywords: bacterial species, crude methanolic extract, flavonoids, maximum antioxidant activity, inhibitory activity. 


\section{INTRODUCTION}

Plants and plant products have been used as sources of medicine for thousands of years and continue to take centre stage globally in primary health care, mostly in developing Countries (Balunas and Kinghorn, 2005). The use of medicinal plants is on the increase because they appear to be safe for human consumption and often without the immediate side effects that often characterize the use of conventional drugs. The invention of drugs from plants may be one of the solutions in the fight against diseases. Thousands of natural products are currently on clinical trials and some are already confirmed useful in combating some of the diseases (Balunas and Kinghorn, 2005).

The world population is said to be about 5.2 billion people. It is believed that about $80 \%$ of these people of the world live in the underdeveloped countries. The World Health Organization estimates that about $80 \%$ of these people depend almost exclusively on traditional medicine for their primary healthcare needs (Akinyemi, 2000). In the African sub-region, the proportion is much higher (Ajose, 2007). In recent years, medicinal plants have represented a primary health source for the pharmaceutical industry. Not less than 400 compounds derived from plants are currently used in the preparation of drugs, such as vincristine and vinblastine used in the treatment of cancer (Ajose, 2007) and quinine and artemisinin used as antimalarials (Phillipson, 1991).. Medicinal plants are the "backbone" of traditional medicine, which means more than 3.3 billion people in the less developed countries utilize medicinal plants on a regular basis (Davidson-Hunt, 2000). Since the beginning of human civilization, plants have been used by mankind for their therapeutic values. Nature has been a source of medicinal agents for thousands of years and an impressive number of modern drugs have been produced from natural sources. Many of these isolations were based on the information that the agents are used in traditional medicine. The plant-based traditional medicine systems continue to play an essential role in health care (Owolabi et al., 2007).

World Health Organization (WHO, 1977) defined a medicinal plant as any plant, which in one or more of its organs contains substances that can be used for therapeutic purposes or which, are precursors for the synthesis of drugs. Such a plant will have its parts including leaves, roots, rhizomes, stems, barks, flowers, fruits, grains or seeds, employed in the control or treatment of a disease condition and therefore contains chemical components that are biologically active. These bioactive components are often referred to as phytochemicals and are responsible for protecting the plant against microbial infections or infestations by pests (Abo et al., 1991; Liu, 2004; Nweze et al., 2004). Furthermore, WHO (2001) defined medicinal plants as herbal preparations produced by subjecting plant materials to extraction, fractionation, purification, concentration or other physical or biological processes which may be produced for immediate consumption or as a basis for herbal products. Plants containing beneficial phytochemicals may 
supplement the needs of the human body by acting as natural antioxidants (Boots et al., 2008).

Several works have been carried out to verify and confirm the traditional uses of $Z$. zanthoxyloides in Nigeria, but investigations on its antioxidant and antibacterial potencies remained scanty. Thus, this work was undertaken to evaluate the antioxidant and antimicrobial properties of the flavonoid-rich fraction of $Z$. zanthoxyloides leaf.

\section{MATERIALS AND METHODS}

Sample Collection and Identification of Plant

Z. zanthoxyloides leaves were obtained from a farmland in Ikare Akoko, Ondo State, Nigeria. Identification was done at the Herbarium of the Department of Plant Science and Biotechnology, Adekunle Ajasin University, Akungba Akoko, Ondo State.

\section{Sample Preparation and Extraction of $Z$. zanthoxyloides Leaf}

The leaves were washed, air-dried at room temperature in the laboratory to prevent ultraviolet rays from altering the chemical constituents (Das et al., 2010). The dried leaves were then pulverized to a fine powder using an electric grinding machine (Marlex CM/L7371373) to produce a homogenous sample with increased surface area. The powder was then stored in a polythene bag until use. Eight hundred grams (800 g) of the sample was soaked in 4 litres of methanol (1:5), for 72 hours and the mixture was filtered using a clean cheese cloth. Crude extract was obtained by concentrating it in a rotary evaporator at a temperature of $50{ }^{\circ} \mathrm{C}$. It was then fractionated using the method of Woo et al., (1980) to obtain flavonoids-rich fraction. Flavonoids determination

Five mililitres of dilute ammonia solution was added to a portion of the fraction, followed by addition of concentrated $\mathrm{H}_{2} \mathrm{SO}_{4}$. A yellow coloration was observed, indicating the presence of flavonoids. The yellow coloration disappeared on standing in accordance with Sofowora (1993).

Source and Maintenance of Test Organisms

The clinical isolates of Staphylococcus aureus (SA), Klebsiella pneumonia (KP) and Moraxella catarrhalis (MC) were obtained from samples of sputum obtained from Adekunle Ajasin University Health Centre, Akungba-Akoko, Ondo State, Nigeria. The viability of the bacterial isolates was maintained by regular transfers unto nutrient agar slants.

Antibacterial Sensitivity Testing of Flavonoid-fraction

The agar diffusion technique of Juliani et al., (2002) was employed. Sterile nutrient agars contained in petri dishes were inoculated with the standardized bacteria inocula using sterile cotton swabs. Wells of $6 \mathrm{~mm}$ diameters were cut and filled with $0.3 \mathrm{ml}$ of each extract at concentrations ranging from $100 \mathrm{mg} / \mathrm{ml}$ to $250 \mathrm{mg} / \mathrm{ml}$. Ciprofloxacin (standard antibiotics) was used as the positive control while methanol, the solvent, served as the negative control. The extract was allowed to diffuse into the medium for $1 \mathrm{~h}$, after which the plates were incubated at $37^{\circ} \mathrm{C}$ for $24 \mathrm{~h}$. Thereafter, the diameters of zones of inhibition were measured in millimeter. 
Determination of Minimum Inhibitory Concentration

The agar dilution technique was used to determine the minimum inhibitory concentration of the plant extract.

\section{Determination of DPPH Radical Scavenging} Activity

The DPPH (1, 1-diphenyl-2-picrylhydrazyl) radical scavenging activity of flavonoidsrich fraction was measured by using assay method described by Shimada et al. (1992), with slight modifications. $1 \mathrm{~mL}$ each of flavonoids-rich fraction at different concentrations $(0.2-0.8 \mathrm{mg} / \mathrm{ml})$ was added to $1 \mathrm{~mL} 0.1 \mathrm{mM}$ DPPH dissolved in $95 \%$ ethanol. The mixture was shaken vigorously and left in the dark at room temperature for 30 minutes. The absorbance was read at $517 \mathrm{~nm}$. Ethanol (95\%) was used as a blank. The control solution consisted of $0.1 \mathrm{~mL}$ of $95 \%$ ethanol and $2.9 \mathrm{~mL}$ of DPPH solution. Analyses were carried out in triplicates. The scavenging activity was estimated based on the percentage of DPPH radical scavenged as the following equation:

DPPH Scavenging effect $(\%)=\left(\right.$ Abs $_{\text {control }}-$ Abs sample $) \times 100 /$ (Abs control)

$\mathrm{EC}_{50}$ value, the effective concentration that could scavenge $50 \%$ of the DPPH radicals was estimated from scavenging effect (\%) plot, using a non-linear regression plot. Ascorbic acid standard was used as positive reference.

\section{Determination of Hydrogen Peroxide \\ Scavenging Activity}

The ability of the flavonoid-rich fraction to scavenge hydrogen peroxide was determined according to the method of
Ruch et al. (1989) as described by Keser et al. (2012) with slight modifications. A solution of hydrogen peroxide ( $4 \mathrm{mM})$ was prepared in $0.2 \mathrm{M}$ phosphate buffer $(\mathrm{pH}$ 7.4). Varying concentrations of the flavonoids-rich fraction $(0.2-0.8 \mathrm{mg} / \mathrm{mL})$ in distilled water were added to $0.6 \mathrm{ml}$ of 4 $\mathrm{mM}$ hydrogen peroxide solution. Absorbance value of test samples (As) were read at $230 \mathrm{~nm}$ after 10 minutes against a blank solution containing the phosphate buffer without hydrogen peroxide. Absorbance of hydrogen peroxide was taken as the control. Ascorbic acid was used as a standard antioxidant. The percentage of scavenging effect was calculated by comparing the absorbance values of the control and test samples using:

\% Scavenging Capacity (\% Scavenged $\left.\left[\mathrm{H}_{2} \mathrm{O}_{2}\right]\right)=[(\mathrm{AC}-\mathrm{AS}) / \mathrm{AC}] \times 100$

$I_{50}$ values were estimated from the \% inhibition versus concentration plot, using a non-linear regression plot.

\section{Determination of Ferric Reducing Antioxidant Property (FRAP)}

The reducing power of flavonoid-rich fraction was measured according to the method of Oyaizu (1986) with slight modifications. An aliquot of $1 \mathrm{ml}$ of different concentrations $(0.2-0.8 \mathrm{mg} / \mathrm{ml})$ of Flavonoid-rich fraction (0.2 M PBS, pH 6.6) was mixed with $1 \mathrm{ml}$ of $1 \%$ potassium ferric cyanide solution. The mixture was incubated at $50^{\circ} \mathrm{C}$ for 30 minutes followed by the addition of $1 \mathrm{ml} \mathrm{10 \%} \mathrm{(w/v)} \mathrm{TCA.} 1 \mathrm{ml}$ of the incubation mixture was added with $1 \mathrm{ml}$ of distilled water and $0.2 \mathrm{ml}$ of $0.1 \%$ $(\mathrm{w} / \mathrm{v})$ ferric chloride in test tubes. After a 10 
min reaction time, the absorbance of resulting solution was read at $700 \mathrm{~nm}$. Higher absorbance suggested stronger reducing power. Ascorbic acid was used as the reference antioxidant. An aqueous solution of known $\mathrm{Fe}$ (II) concentrations $\left(\mathrm{FeSO}_{4} \cdot 7 \mathrm{H}_{2} \mathrm{O} ; \quad 2.0, \quad 1.0,0.5,0.25,0.125\right.$, $0.063 \mathrm{mM}$ ) was used for calibration. Results were expressed as $\mathrm{mM} \mathrm{Fe}^{2+} / \mathrm{mg}$ extract. All the tests were performed in triplicate.

The $\mathrm{EC}_{50}$ of extracts were calculated from the graph of A700 versus extracts concentration.

\section{Determination of Superoxide Radical Scavenging Activity (SRSA)}

The method described by Xie et al. (2008) was used to determine SRSA. Samples (1 $\mathrm{mg} / \mathrm{mL}$ final concentration) were dissolved in $50 \mathrm{mM}$ Tris- $\mathrm{HCl}$ buffer, $\mathrm{pH} 8.3$ containing $1 \mathrm{mM}$ EDTA and $80 \mu \mathrm{L}$ was transferred into a clear bottom microplate well; $80 \mu \mathrm{L}$ of buffer was added to the blank well. This was followed by addition of $40 \mu \mathrm{L} 1.5 \mathrm{mM}$ pyrogallol (dissolved in $10 \mathrm{mM} \mathrm{HCl}$ ) into each well in the dark and the change in the rate of reaction was measured immediately at room tem perature over a period of 4 min using a spectrophotometer at a wavelength of $420 \mathrm{~nm}$. The superoxide scavenging activity was calculated using the following equation:

Superoxide scavenging activity (\%) = $\left(\triangle \mathrm{Abs} / \mathrm{min}_{\mathrm{b}}-\triangle \mathrm{Abs} / \mathrm{min}_{\mathrm{s}}\right) / \triangle \mathrm{Abs} / \mathrm{min}_{\mathrm{b}} \times 100$ where $b$ and $s$ are blank and sample, respectively.

\section{Statistical Analysis}

Results were expressed as mean \pm standard error. The data were statistically analyzed using t-test and Duncan's multiple range tests. Differences were considered statistically significant at $p<0.05$ using SPSS and GraphPad Prism version 7.0 (GraphPad Software, San Diego, CA, USA). 


\section{RESULTS}

\section{Antimicrobial Activity}

Figure 1 shows the zones of inhibition of Klebsiella pneumoniae at different concentrations of flavonoids-rich fraction of Z. zanthoxyloides compared to the control (ciprofloxacin).

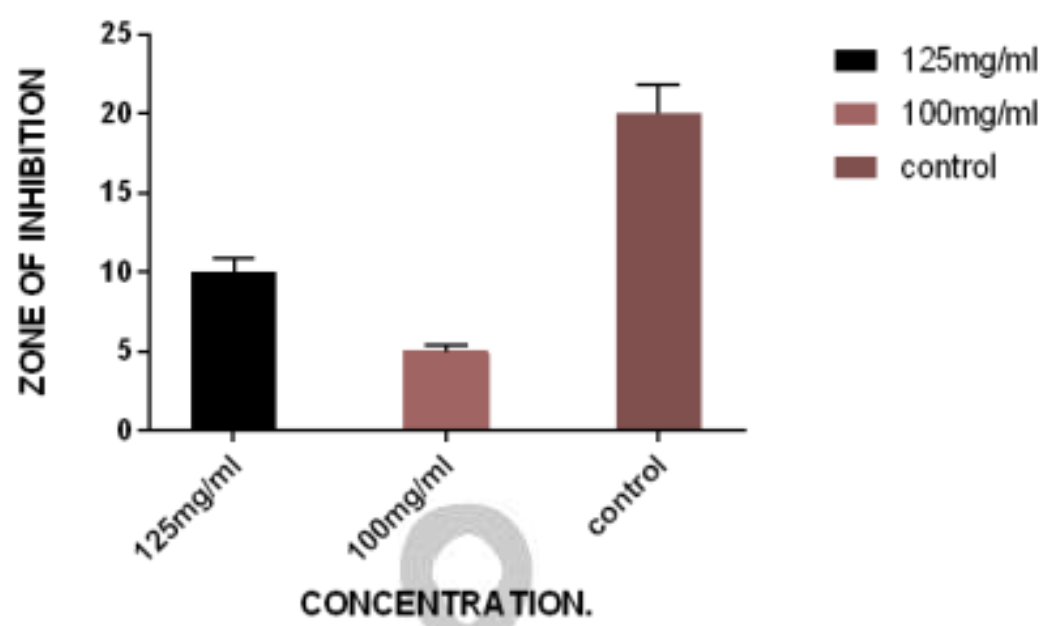

\section{ZONE OF INHIBITION of klebsiella pneumonia}

Figure 2 shows the zone of inhibition of Moraxella catarrhalis at different concentrations of the flavonoids-rich fraction of Z. zanthoxyloides plant compared with the control (ciprofloxacin).

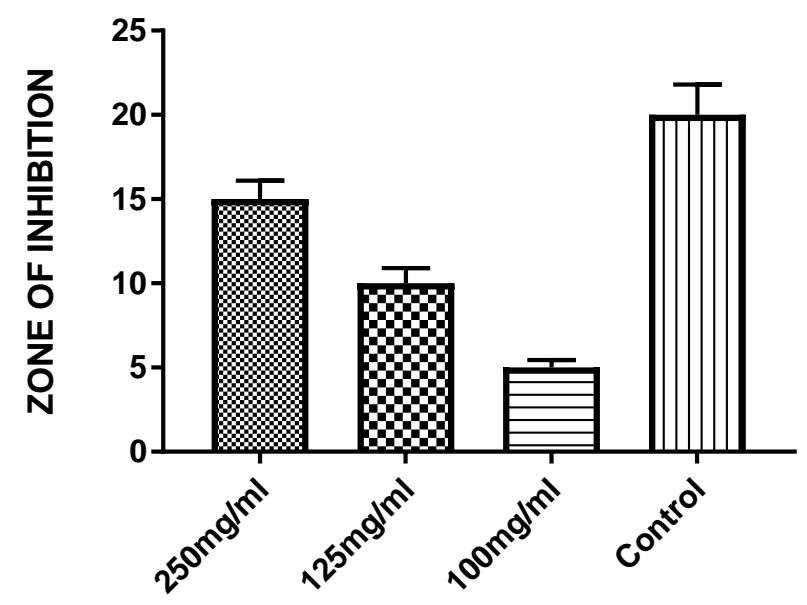
$250 \mathrm{mg} / \mathrm{ml}$
$125 \mathrm{mg} / \mathrm{ml}$
$100 \mathrm{mg} / \mathrm{ml}$
m Control

CONCENTRATION.

ZONE OF INHIBITION OF Moraxella catarrhalis 
Figure 3 shows the DPPH radical scavenging activity of ascorbic acid, (the reverence antioxidant) and that of flavonoids-rich fraction of $Z$. zanthoxyloides, at a concentration ranging from $0.2 \mathrm{mg} / \mathrm{ml}-0.8 \mathrm{mg} / \mathrm{ml}$. The extract showed a concentration dependent increase in DPPH scavenging activity. The plant extract had significantly $(p<0.05)$ lower scavenging activity when compared to ascorbate.

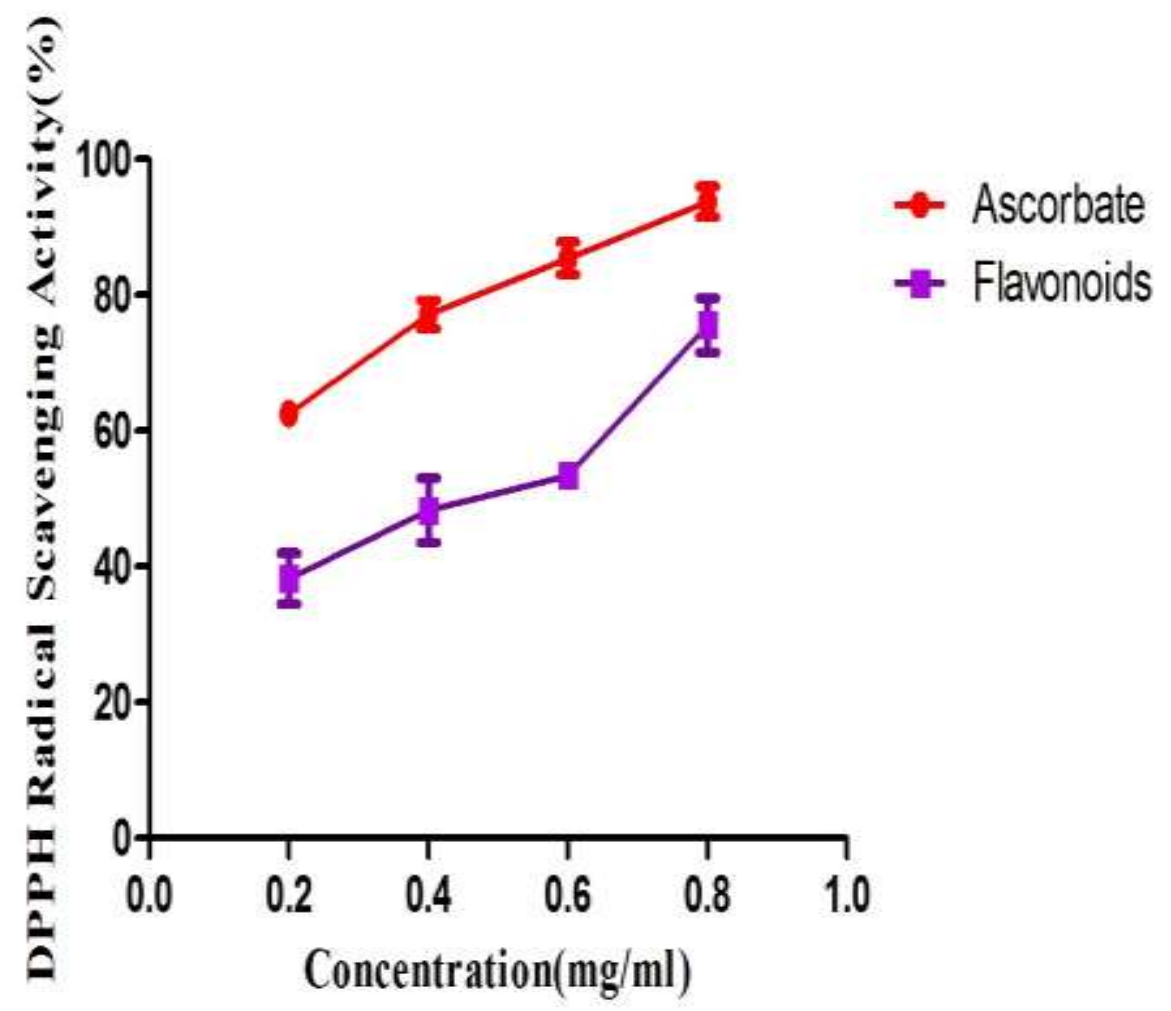

Figure 3: DPPH radical scavenging activity of flavonoid fraction of $Z$. zanthoxyloides leaf. 
Figure 4 shows the $\mathrm{EC}_{50}$ values of flavonoid-rich fraction of Z. zanthoxyloides in scavenging DPPH radical as compared to ascorbate, the reference antioxidant. The flavonoids-rich fraction scavenged the radical to a $50 \%$ inhibition at concentration of $0.054 \pm 0.001$. It has significantly $(p<0.05)$ higher $\mathrm{EC}_{50}$ values when compared to ascorbate.

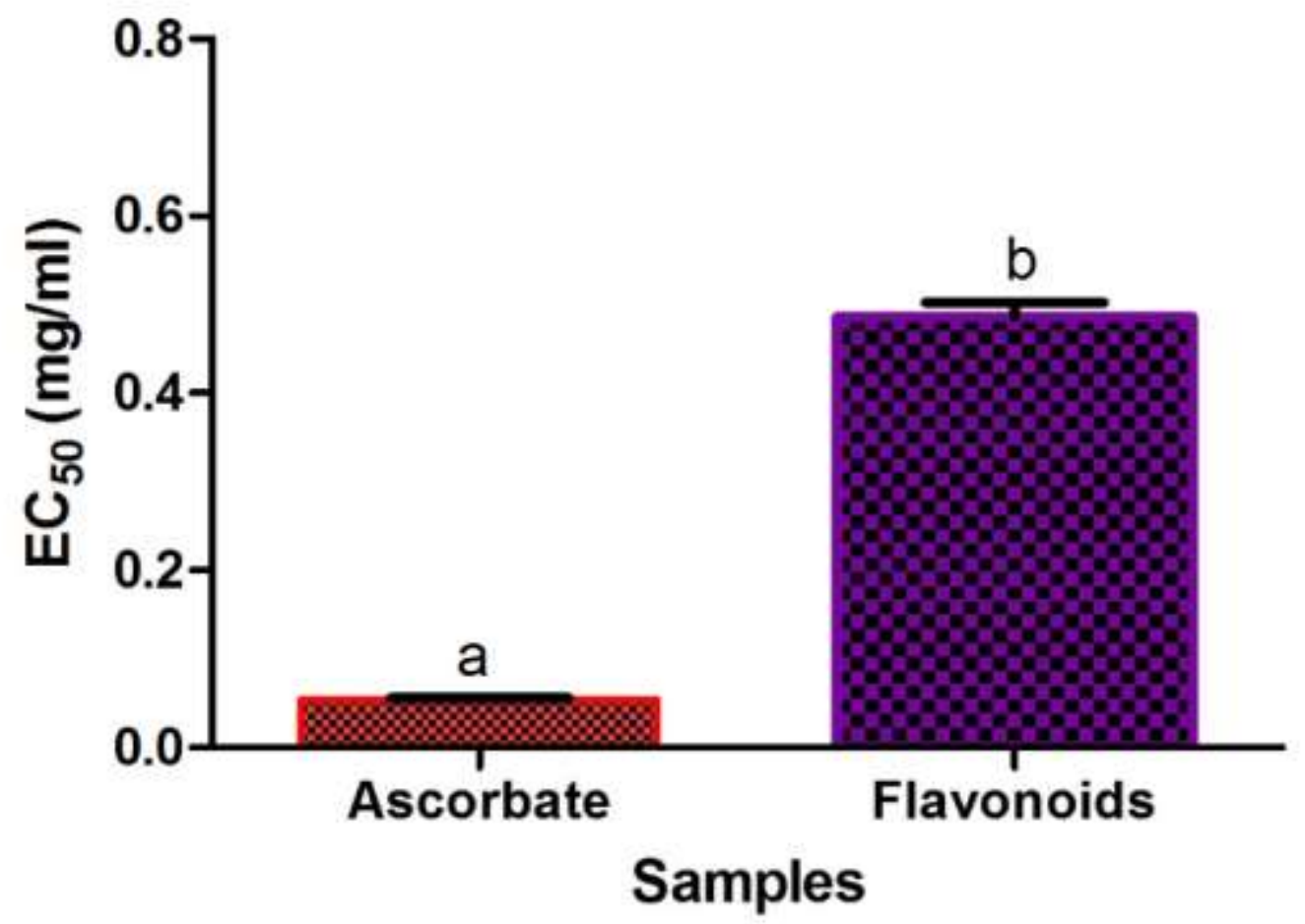

Figure 4: $\mathrm{EC}_{50}$ values of ascorbate and flavonoids fraction of $Z$. zanthoxyloides leaf against DPPH radical.

Results are expressed as means \pm standard error of triplicate determinations $(n=3)$. Values with the same superscripts do not differ significantly while values with different superscripts are significantly different $(p<0.05)$ from one another. 
Figure 5 shows the ferric reducing antioxidant ability of ascorbate, the reference antioxidant and that of flavonoids-rich fraction of $Z$. zanthoxyloides leaf. Flavonoids significantly $(p<0.05)$ reduced $\mathrm{Fe}^{2+}$ at different concentrations when compared with ascorbate. At all concentrations, there was significant difference between flavonoids and ascorbate at concentration of $0.2 \mathrm{mg} / \mathrm{ml}, 0.4 \mathrm{mg} / \mathrm{ml}, 0.6 \mathrm{mg} / \mathrm{ml}$ and $0.8 \mathrm{mg} / \mathrm{ml}$.

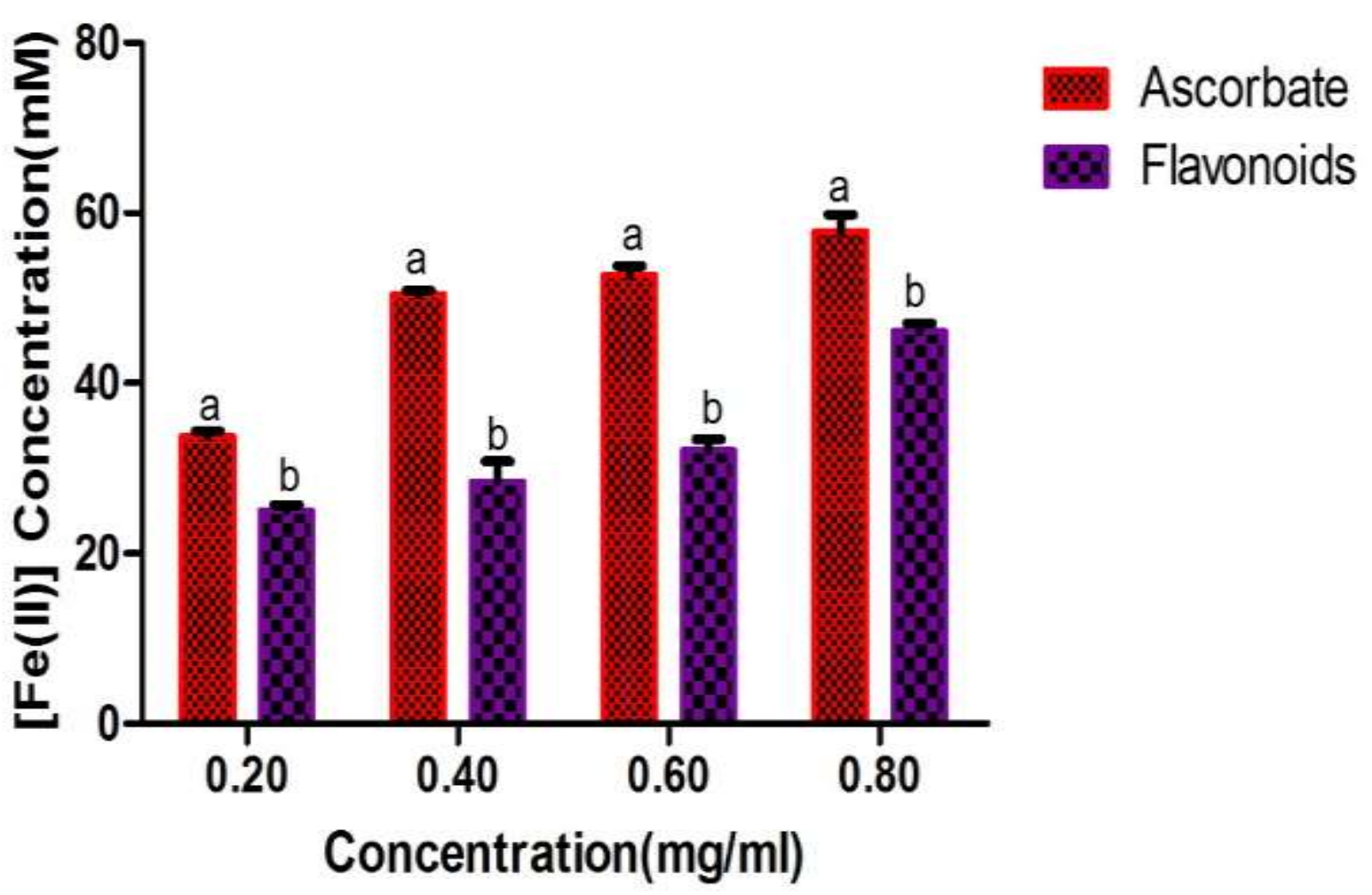

Figure 5: Ferric reducing antioxidant properties of ascorbate and flavonoids-rich fraction of $Z$. zanthoxyloides leaf extract.

Results are expressed as means \pm standard error of triplicate determinations $(n=3)$. Values with the same superscripts do not differ significantly while values with different superscripts are significantly different $(p<0.05)$ from one another. 
The hydrogen peroxide radical scavenging activities of ascorbic acid and flavonoid-rich extract of $\mathrm{Z}$. zanthoxyloides are presented in Figure 6. The extract produced a significantly higher $(p<0.05)$ scavenging activity at concentrations of $0.2 \mathrm{mg} / \mathrm{ml}$ and $0.4 \mathrm{mg} / \mathrm{ml}$ when compared with ascorbic acid (control) and a lower scavenging activity at concentrations $0.6 \mathrm{mg} / \mathrm{ml}$ and $0.8 \mathrm{mg} / \mathrm{ml}$ when compared with the control.

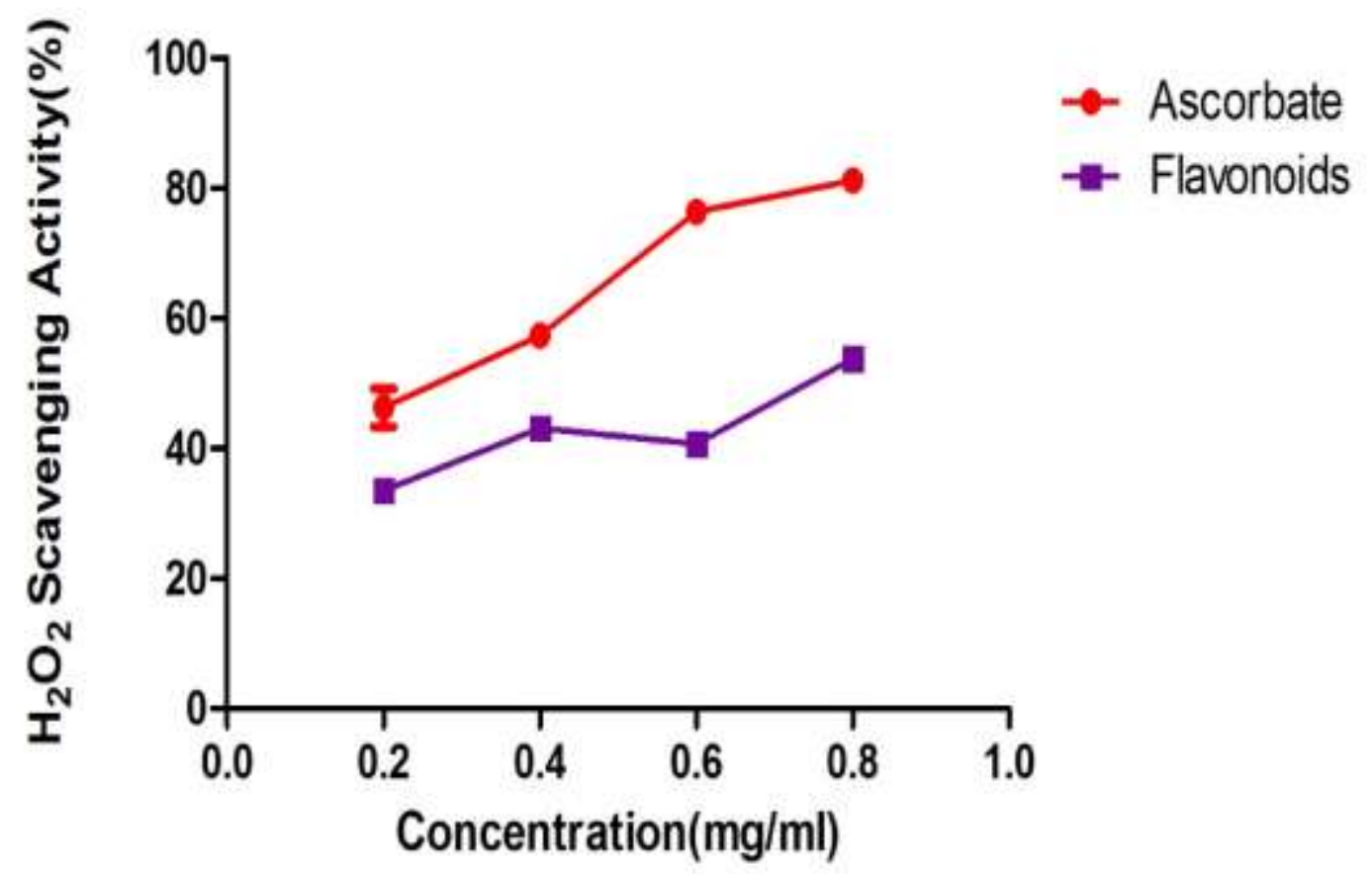

Figure 6: Hydrogen peroxide scavenging activity of flavonoids fraction of Z. zanthoxyloides leaf extract.

Figure 7 shows $\mathrm{EC}_{50}$ values of the flavonoid-rich extract compared to the control. The flavonoid-rich extract scavenged the radical to a $50 \%$ inhibition at a concentration of $0.75 \pm 0.04$. The $\mathrm{EC}_{50}$ value of the extract was significantly higher when compared with the control. 


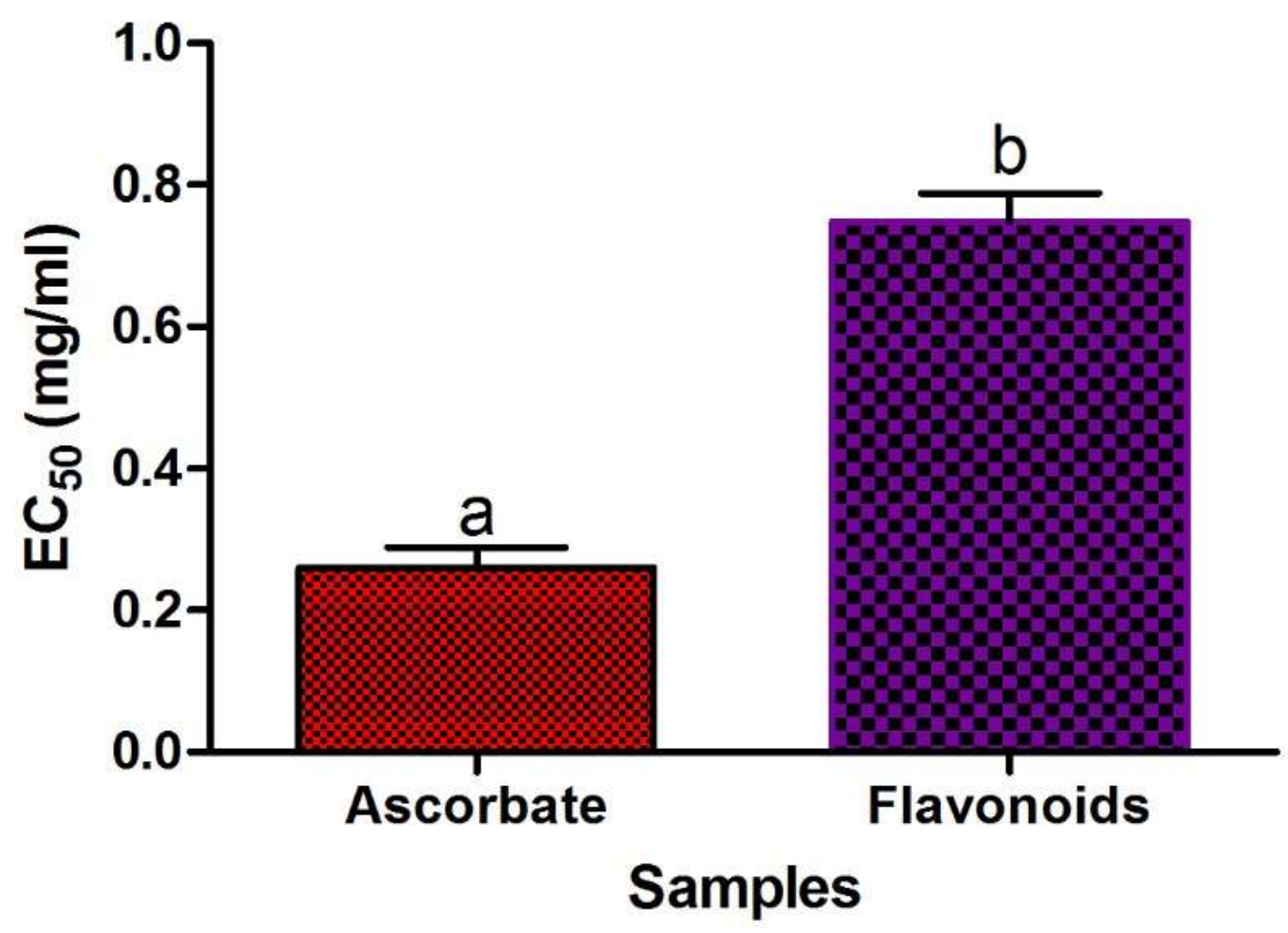

Figure 7: $\mathrm{EC}_{50}$ values of ascorbate and flavonoids-rich fraction of $\mathrm{Z}$. zanthoxyloides leaf against hydrogen peroxide radical.

Results are expressed as means \pm standard error of triplicate determinations $(n=3)$. Values with the same superscripts do not differ significantly while values with different superscripts are significantly different $(p<0.05)$ from one another. 
The superoxide radical scavenging activities of flavonoids-rich extract of Z. zanthoxyloides leaf are presented in

Figure 8. The extract had a lower scavenging activity compared to ascorbic acid (control).

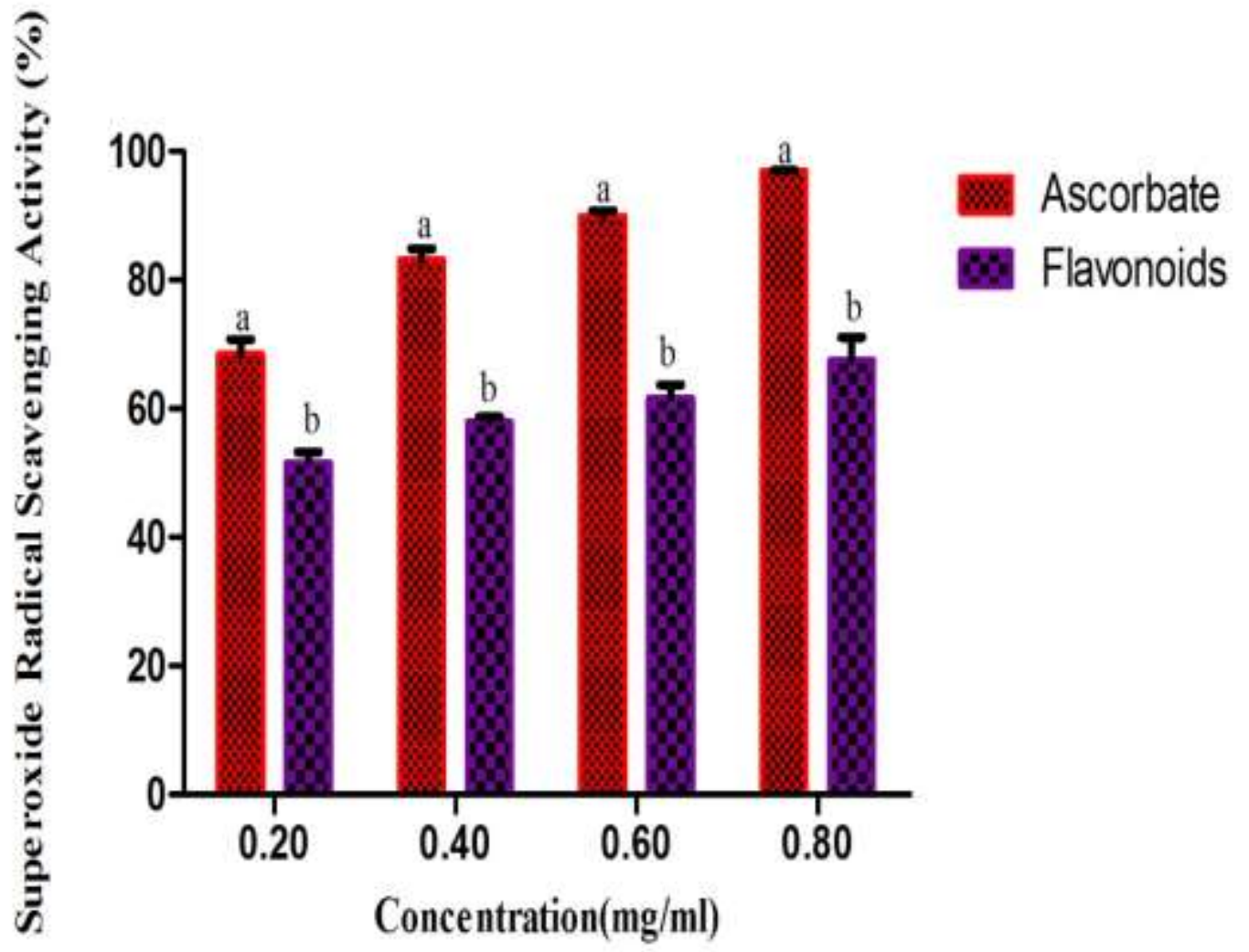

Figure 8: $\quad$ Superoxide Radical Scavenging Activity (\%)

Results are expressed as means \pm standard error of triplicate determinations $(n=3)$. Values with the same superscripts do not differ significantly while values with different superscripts are significantly different $(p<0.05)$ from one another. 
Figure 9 shows $\mathrm{EC}_{50}$ values of the flavonoids-rich extract in scavenging for the superoxide radical as compared with ascorbic acid. Flavonoids-rich extract scavenged the radical to a $50 \%$ inhibition at a concentration of 0.13 \pm 0.01 . The extract has significantly higher $\mathrm{EC}_{50}$ values when compared with the control.

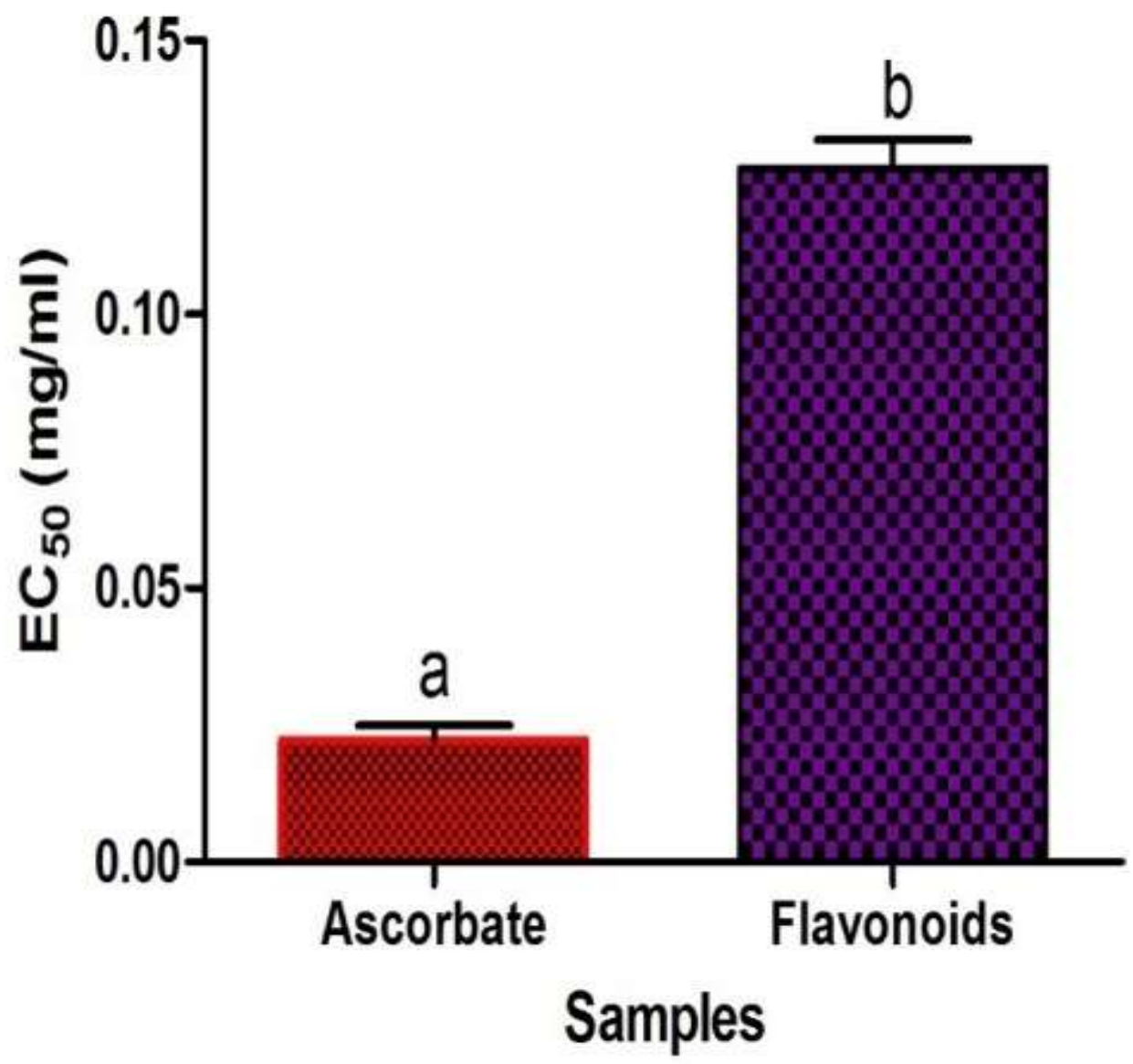

Figure 9: $\quad$ Effect of $\mathrm{EC}_{50}$ values of ascorbate and Z. zanthoxyloides leaf extract on superoxide radical. 2021 January Edition | www.jbino.com | Innovative Association 
Results are expressed as means \pm standard error of triplicate determinations $(n=3)$. Values with the same superscripts do not differ significantly while values with different superscripts are significantly different $(p<0.05)$ from one another.

\section{DISCUSSION}

Phytochemical constituents which are present in plant samples are known to be biologically active compounds and are responsible for different activities such as antimicrobial, antioxidant, antifungal, anticancer and antidiabetic (Hossain and Nagooru, 2011).

The variation in the antimicrobial activity of the plant extracts can be attributed to inoculum size, type of media used, type of solvent used for extraction, extraction procedure, incubation time and temperature, part of the plant used and its time of collection, method of extraction procedure, method of antimicrobial assay (Jahan et al., 2011).

The results of the antibacterial activity showed good activity on all the strains tested at different concentrations (Figure 1). The study showed that ciprofloxacin which served as the control was more active than the plant extract which was revealed by the mean diameter zone of inhibition (Figures 2).

The microbial investigations revealed that the flavonoids-rich fraction of $z$. zanthoxyloides leaf showed an inhibitory activity against the bacteria Moraxella cattarhalis at $50 \mathrm{mg} / \mathrm{ml}$, Staphlococcus aureus at $125 \mathrm{mg} / \mathrm{ml}$ and Klebsiella pneumonia at $500 \mathrm{mg} / \mathrm{ml}$ similar to that of the standard antibiotic. This is in consonance with Jindal and Kumar (2017) who evaluated the antimicrobial activity of Tridax procumbens L. against human pathogens. The zones of inhibition of Moraxella catarrhalis at $250 \mathrm{mg} / \mathrm{ml}(15$ $\mathrm{mm}$ ), $125 \mathrm{mg} / \mathrm{ml}(10 \mathrm{~mm}), 100 \mathrm{mg} / \mathrm{ml}(5$ $\mathrm{mm}$ ) and Klebsiella pneumonia $125 \mathrm{mg} / \mathrm{ml}$ (10 mm), $100 \mathrm{mg} / \mathrm{ml}(5 \mathrm{~mm})$.

DPPH radicals are widely used in the model system to evaluate the scavenging activities of several natural compounds. DPPH is a stable nitrogen-centered free radical commonly used for testing radical scavenging activity of the compound or plant extracts. When the stable DPPH radical accepts an electron from the antioxidant compound, the violet color of the DPPH radical is reduced to yellow colored diphenylpicrylhydrazine radical which is measured colorimetrically. Substances having this property are 2021 January Edition | www.jbino.com | Innovative Association 
considered as free radical scavengers (Dehpour et al., 2009). The DPPH radical has a single electron and shows maximum absorbance at $517 \mathrm{~nm}$. It is commonly used to determine the scavenging activity of some organic compounds such as phenolics, flavonoids, as well as protein hydrolysates (Sun et al., 2013). As DPPH reacts with a proton-donating substance, the radical is scavenged, leading to a reduction in absorbance (Shimada et al., 1992).

The effects of phenolic compounds on DPPH radical scavenging are thought to be due to their hydrogen donating ability (Ghimeray et al., 2009) to the unstable DPPH free radical that accepts an electron or hydrogen to become a stable diamagnetic molecule (Siddaraju and Dharmesh, 2007). The flavonoids-rich fraction showed considerable radical scavenging activity in a concentrationdependent manner $(0.20-0.80 \mathrm{mg} / \mathrm{ml})$ as shown in Figure 3 . The flavonoids-rich fraction $(0.4857 \pm 0.0166 \mathrm{mg} / \mathrm{ml})$ exhibited a good potential to act as a free radical scavenger with $\mathrm{EC}_{50}$ for DPPH inhibition comparable to that of ascorbate $10.0543 \pm$ $0.0014 \mathrm{mg} / \mathrm{ml}$ ) which is well known as free radical scavenger as shown in Figure 4. These results were found to be similar to that obtained by Abalaka et al. (2011) for in vitro antioxidant and free radical scavenging potential of Ziziphus mauritiana and Ziziphus spinachristri leaf. The observed antioxidant activity may be due to the neutralization of free radicals (DPPH), either by transfer of hydrogen atom or by transfer of an electron (Sahoo et al., 2013).
The FRAP assay is a quick and simple test for estimating the antioxidant capacity of any component in a reaction medium in terms of its reducing power. Ferric reducing antioxidant power assay is often utilized in evaluating the ability of natural antioxidants such as flavonoids, polyphenols and protein hydrolysates to donate protons (Yildirim et al., 2000). The ability of bioactive compounds to reduce ferric ions has a strong correlation with their antioxidative properties. FRAP method is based on the reduction of $\mathrm{Fe}^{3+}$ to $\mathrm{Fe}^{2+}$ by antioxidants in acidic medium (Benzie and Strain, 1996). The flavonoid fraction exhibited low ferric reducing properties as shown in Figure 5. This correlates well with a study by Sumazian et al. (2010).

$\mathrm{H}_{2} \mathrm{O}_{2}$ is capable of reacting with major cell components and participate in lipid peroxidation and also causing DNA damage (Sahreen et al., 2011). The $\mathrm{H}_{2} \mathrm{O}_{2}$ scavenging activity of flavonoids-rich extract and its $\mathrm{EC}_{50}$ values were presented in Figure 6 and 7 respectively. The results reveal a higher antioxidant activity of the extract at concentrations 0.2 and 0.4 $\mathrm{mg} / \mathrm{ml}$ than the standard at concentrations 0.6 and $0.8 \mathrm{mg} / \mathrm{ml}$, the scavenging activity was significantly lower than that of the standard. The extract scavenged the radical to a $50 \%$ inhibition at a concentration of $0.7482 \pm 0.0397$.

Superoxide anion are precursors to active free radicals and plays an important role in the formation of other ROS such as hydrogen peroxide, hydroxyl radical and singlet oxygen which include oxidative damage in lipids, proteins and DNA (Pietta, 2000). Superoxide radical is normally 
formed first and its effect can be magnified because it produces other kinds of free radicals and oxidizing agents. Superoxide anions have the potential of reacting with biological macromolecules and have been implicated in several pathophysiological processes due to its transformation into more reactive species, such as hydroxyl radicals that initiate lipid peroxidation. Also, superoxide has been observed to directly initiate lipid peroxidation (Wickens, 2001). Superoxide anion radical is known to be very harmful to cellular components, and can damage cells and tissues, leading to disease (Sun et al., 2013).

The flavonoids-rich fraction of the plant exhibited significantly $(p<0.05)$ lower scavenging activity when compared to ascorbic acid. Ascorbic acid showed an excellent degree of scavenging activity on the superoxide anion radical $\left(E_{50}=\right.$ $0.0223 \pm 0.0026$ ) while the flavonoids-rich fraction also showed effective scavenging of the superoxide anion radical with a relatively lower inhibitory effect $\left(E C_{50}=0.1267 \pm 0.0052\right)$. This is in accordance with the study of Zhao et al. (2011) which showed low superoxide scavenging activity of anthocyanins from three berries. The presence of secondary metabolites like flavonoids, carotenoids and triterpenes in higher plants have excellent antioxidant activity by scavenging reactive oxygen species which prevent possible damage to cellular components such as DNA, proteins and lipids (Ksouri et al., 2013).
It is interesting to note from this study that the flavonoids-rich extract of $Z$. zanthoxyloides possesses potent antibacterial and antioxidant properties. This suggests its potentials as a natural source of antioxidant and antimicrobial agent in drug design.

\section{REFERENCES}

Abalaka, M.Z., Mann, A. and Adeyemo, S.O. (2011). Studies on in-vitro antioxidant and free scavenging potential and phytochemical screening of leaves of Ziziphus mauritiana L. and Ziziphus spinachristi L. compared with Ascorbic acid. Journal of Medical Genetics and Genomics. 3(2): 28-34.

Abo, K.A., Ogunleye, V.O. and Ashidi, J.S. (1991). Antimicrobial poteintial of Spondias mombin, Croton zambesicus and Zygotritonia crocea. J. Pharm. Res. 5(13): 494-497.

Ajose, F.O.A. (2007). Some Nigerian plants of dermatologic importance. Int. J. Dermatol. 46:48-55

Akinyemi, B. (2000). Recent concept in plaque formation. J. Clin. Pathol. 30:13-16. Balunas, M.J. and Kinghorn, A.D. (2005). Drug discovery from medicinal plants. Life Sciences. 78 (5): 431-441.

Benzie, I.F.F. and Strain, J.J., (1996). The Ferric Reducing Ability of Plasma (FRAP) as a measure of antioxidant power. The FRAP assay. Anal. Biochem., 239:70-76.

\section{CONCLUSION}


Boots, A.W., Haenen, G.R. and Bast, A. (2008). Health effects of quercetin: From antioxidant to nutraceutical. Eur. J. Pharmacol. 585: 325-337. [CrossRef] [PubMed].

Das, K., Tiwan, R. K. S. and Shivasteva, D. K. (2010). Techniques for Evaluation of Medicinal Plant Products as Anti-microbial Agent : Current Methods and FutureTrends. Journal of Medicinal Plants Research 4: 104 -111 .

Davidson-Hunt I. (2000). Ecological ethno botany: stumbling toward new practices and paradigms. MASA J. 16:1-13.

Dehpour, A.A., Ebrahimzadeh, M.A., Nabavi, S.F. and Nabavi, S.M. (2009). Antioxidant activity of methanol extract of Ferula assafoetida and its essential oil composition. GrasasAceites 60: 405-412.

Ghimeray, A.K., Jin, C. Ghimine, B.K. and Cho, D.H. (2009). Antioxidant activity and quantitative estimation of azadirachtin and nimbin in Azadirachta indica A. Juss grown in foothills of Nepal. Afr. J. Biotechnol., 8: 3084-3091. Direct Link ।

Hossain. M. A. and Nagooru. M. R., (2011). Biochemical profiling and total flavonoids contents of leaves crude extract of endemic medicinal plant corydyline terminal is L. Kunth. Pharmacognosy Journal 3(24):25-29.

Jahan, F., Lawrence, R., Kumar, V. and Junaid, M., (2011). Evaluation of antimicrobial activity of plant extracts on antibiotic susceptible and resistant
Staphylococcus aureus strains. J. Chem. Pharm. Res. 3(4):777-789.

Jindal, A. and Kumar, P. (2012). Antimicrobial activity of Tridax procumbens against human pathogens. International Journal of Pharmaceutical Sciences and Research. 3(9): 3481-3485.

Juliana Jr, H. R., Biuruum, F., Koroch, A. R., Olivia, M. M., Demo, M. S., Trippi, V. S and Zygadlo, J. A (2002). Chemical constituents and antimicrobial activity of the essential oil of Lantana xenica. Planta Medica, 68:762-764.

Keser, S., Celik, S., Turkoglu, S., Yilmaz O., and Turkoglu, I. (2012) Hydrogen Peroxide Radical Scavenging and Total Antioxidant Activity of Hawthorn. Chemistry Journal. 02(01): 9-12.

Ksouri, W.M., Medini, F., Mkadmini, K., Legault, J., Magne, C. and Abdelly, C., (2013). LC-ESI-TOF-MS identification of bioactive secondary metabolites involved in the antioxidant, anti-inflammatory and anticancer activities of the edible halophyte Zygophyllum album Desf. Food Chem. 139: 1073-1080.

Liu, R.H., (2004). Potential synergy of phytochemicals in cancer prevention: mechanism of action; J Nutr. 134(12 Suppl): 3479S- 3485S.

Nweze, E.L., Okafor, J.L. and Njoku, O. (2004). Antimicrobial Activities of Methanolic extracts of Trume guineesis (Scchumn and Thorn) and Morinda lucinda 
used in Nigerian Herbal Medicinal practice. J. Biol. Res. Biotech. 2(1): 34-46.

Owolabi J., Omogbai E.K.I. and Obasuyi O. (2007). Antifungal and antibacterial activities of the ethanolic and aqueous extract of Kigella africana (Bignoniaceae) stem bark. Afr. J. Biotechnol. 6: 882-885.

Oyaizu, M.(1986). Studies on products of browning reactions: antioxidative activities of 581 products of browning reaction prepared from glucosamine, Jpn. J. Nutr. 44 (1986)582 307-315.

Phillipson, J.D. (1991). Assays for antimalarial and amoebicidal activities. In: Hostettmann $\mathrm{K}$,

Dey PM, Harborne JB. Methods in Plant Biochemistry. 6:138, London, Academic Press.

Pietta, P.G., (2000). Flavonoids as antioxidants. J. Nat. Prod. 63: 1035.

Ruch, R.J., Cheng, S.J. and Klaunig, J.E. (1989) Prevention of cytotoxicity and inhibition of intracellular communication by antioxidant catechins isolated from Chinese green tea. Carcinogenesis, 10:1003-1008

Sahoo, S., Goutam, G., Das D., and Nayak, S., (2013). Phytochemical investigation and in vitro antioxidant activity of an indigenous medicinal plant activity of an indigenous medicinal plant Alphina nigra B.L. Burtt. Asian Pac. J. Trop. Biomed. 3(11): 871-876.
Sahreen, S., Khan, M.R. and Khan, R.A., (2011). Phenolics compounds and antioxidant activities of Rumex hastatus D.Don. leaves. J. Med. Plant Res. 5: 27552765.

Shimada, K., Fujikawa, K., Yahara, K.and Nakamura, T. (1992). Antioxidative properties of Xanthan on the antioxidation of soybean oil in cyclodextrin emulsion. J. Agric. Food Chem; 40:945-948

Siddaraju, M.N. and Dharmesh, S.M. (2007). Inhibition of gastric $\mathrm{H}, \mathrm{K}$-ATPase and Helicobacter pylori growth by phenolic antioxidants of Curcuma amada. J. Agric. Food Chem. 55: 7377-7386. CrossRef । Direct Link |

Sofowora, E. A. (1993). Medicinal Plants and Traditional Medicine in Africa. Spectrum Books Ltd, Ibadan, Nigeria. Pp 289.

Sumazian, Y., Syahida, A., Hakiman, M. and Maziah, M., (2010). Antioxidant activities, flavonoids, ascorbic acid and phenolic contents of Malaysian vegetables. Journal of Medicinal Plants Research 4(10): 881890.

Sun, S., Ma, M., Lin, Q., Yang, T. and Niu, H. (2013). Systematic Investigation of Antioxidant Activity of Egg White Protein Hydrolysates Obtained by Pepsin. Advance Journal of Food Science and Technology 5(1): 57-62.

WHO (1977). Resolution -Promotion and Development of Training and Research in 
Traditional Medicine. WHO document No: 30-49.

WHO (2001). Legal Status of Traditional Medicine and Complementary/ Alternative medicine: A world wide review. WHO Publishing 1.

Wickens, A.P., (2001). Aging and the free radical theory. Respiratory Physiol., 128: 379-391.

Woo, W.S., Shin, K.H. and Kang, S.S. (1980). Chemistry and Pharmacology of Flavone C- Glycoside from ziziphus seeds. Kor J of Pharmacog. 11 (3-4):141-148.

Xie, Z., Huang, J., Xu, X., and Jin, Z. (2008). Antioxidant activity of peptides isolated from alfalfa leaf protein hydrolysate. Food Chemistry. 111, 370-376.

Yildirim, A., Mavi, A., Oktay, M., Kara, A.A., Algur, O.F. and Bilaloglu, V. (2000). Comparison of antioxidant and antimicrobial activities of tilia (Tilia argenta Desf. Ex DC), sage (Salvia triloba L.) and black tea (Camellia sinensis) extracts. J. Agr. Food Chem. 48: 5030-5034.

Zhao, H., Wang, Z., Cheng, C., Yao, L., Wang, L., Lu, W., Yang, X., and Ma, F., (2011). In-vitro free radical scavenging activities of anthocyanins from three berries. Journal of Medicinal Plants Research 5(32): 7036-7042. 